\title{
AVALIAÇÃO DO APROVEITAMENTO DE ÁGUAS PLUVIAIS ATRAVÉS DE UMA ANÁLISE SISTEMÁTICA DA LITERATURA ${ }^{1}$
}

\author{
Ana Carolina Toledo Rocha ${ }^{2}$ \\ Neimar de Freitas Duarte ${ }^{3}$
}

\begin{abstract}
RESUMO
A água é um bem essencial para a sobrevivência das espécies e para o desenvolvimento econômico e social. Embora a superfície da Terra seja constituída por três quartos de água, apenas uma pequena parcela pode ser utilizada para as atividades humanas. Devido às pressões urbanas, à poluição dos mananciais e à má gestão, atualmente, diversas cidades vêm sofrendo com a crise hídrica. Uma alternativa para diminuir as pressões sobre os recursos hídricos é o aproveitamento de águas pluviais para fins não potáveis. Sabendo disso, o objetivo deste estudo foi realizar uma revisão sistemática da literatura, visando identificar as pesquisas relacionadas à temática abordada. Entre os trabalhos encontrados, foram selecionados 20 estudos em português, 7 em inglês e 3 em espanhol. Observou-se que existem poucos estudos que discutem todas as dimensões para a implantação de um sistema de aproveitamento de águas pluviais. Alguns trabalhos abordam somente a verificação da qualidade da água de chuva, outros analisam apenas as partes do sistema, sem apresentar dimensionamento ou viabilidade econômica. Portanto, verifica-se a necessidade da realização de um estudo que compreenda todas as fases da implantação de um sistema de aproveitamento de águas pluviais.
\end{abstract}

Palavras-chave: Escassez hídrica. Precipitação. Abastecimento de água.

\section{INTRODUÇÃO}

A água é um recurso essencial para o homem, entretanto sua disponibilidade é limitada. Segundo Tucci et al. (2000), devido ao excesso de cargas poluidoras domésticas e industriais, à ocorrência de enchentes e à alta demanda de água, as grandes aglomerações urbanas brasileiras possuem condições críticas de sustentabilidade. Esses fatores,

\footnotetext{
1 Como citar este artigo:

ROCHA, A. C. T.; DUARTE, N. de F. Avaliação do aproveitamento de águas pluviais através de uma análise sistemática da literatura. ForScience: revista científica do IFMG, Formiga, v. 5, n. 2, e00307, out. 2017. Edição especial.

2 Mestranda em Sustentabilidade e Tecnologia Ambiental pelo Instituto Federal de Minas Gerais (IFMG) Campus Bambuí. Graduada em Engenharia Ambiental pela Universidade Federal de Itajubá (Unifei). Currículo Lattes: http://lattes.cnpq.br/1569088682564879. E-mail: anacarolinatoledorocha@gmail.com. 3 Doutorado em Biologia Vegetal pela Universidade Federal de Minas Gerais (UFMG). Professor efetivo e Pró-Reitor de Pesquisa, Inovação e Pós-Graduação do IFMG. Currículo Lattes: http://lattes.cnpq.br/3416823923702282. E-mail: neimar.freitas@ifmg.edu.br.
} 
associados aos baixos índices pluviométricos, têm provocado uma crise hídrica no País, principalmente nos estados de São Paulo, Rio de Janeiro e Minas Gerais.

Por esse motivo, as práticas de reutilização de água vêm se apresentando como um tema atual e importante. Neste caso, essas técnicas devem ser consideradas como parcela de uma atividade mais ampla, que é a utilização eficiente e/ou racional da água, compreendendo a contenção de perdas e desperdícios, e a redução da geração de efluentes e do consumo de água.

A água da chuva é um recurso disponível para toda a população em determinados meses do ano e uma fonte de água doce. A utilização desta água de precipitação é uma questão sustentável e, muitas vezes, econômica.

O aproveitamento da água pluvial é um conceito simples, que permite que as águas da chuva provenientes da cobertura, ao invés de escoarem pelos bueiros, sejam filtradas e armazenadas em um reservatório para seu posterior aproveitamento na irrigação, limpeza, lavagem de roupas, descarga sanitária e demais usos cujos requisitos de potabilidade não sejam necessários (TOMAZ, 2003). Para o público geral, o principal incentivo para investir em tecnologias de conservação de água é gerar economias financeiras, ou seja, poupar dinheiro.

É importante considerar que a coleta e o aproveitamento de águas pluviais reduzem o consumo de água potável fornecida pela companhia de saneamento, conservam a água e reduzem o risco de enchentes. A ANA (2005) enfatiza a utilização de águas de chuva como forma de diminuir o escoamento superficial, o que reduz a carga nos sistemas urbanos de coleta de água de chuva e amortece os picos de cheia, reduzindo as inundações.

Entretanto, Tomaz (2003) destaca que os poluentes presentes no ar dos centros urbanos e polos industriais, como o dióxido de enxofre, óxidos de nitrogênio, chumbo e zinco, alteram as concentrações naturais da água de chuva. $\mathrm{O}$ autor anteriormente citado também aponta que folhas de árvores, poeiras, revestimento do telhado, fezes de aves e animais podem contaminar a água, provocando contaminação por bactérias e parasitas gastrointestinais. Nesse caso, na implantação de projetos de aproveitamento de água pluviais, é importante descartar a primeira água da chuva.

Simões e Reda (2009) afirmam que a qualidade da água precipitada é comparada, pela legislação brasileira, à qualidade do esgoto, exigindo os mesmos cuidados. Portanto, o aproveitamento da água da chuva requer técnicas adequadas que garantam sua aplicação sem comprometer a saúde do usuário. 
A fim de verificar a existência de estudos na área de aproveitamento de águas pluviais, o objetivo deste artigo foi realizar uma pesquisa de caráter descritivo e exploratório fundamentada em revisão sistemática da literatura.

\section{MATERIAIS E MÉTODOS}

A metodologia utilizada foi a de revisão sistemática que, de acordo com Cook et al. (1997), compreende a utilização de técnica científica a fim de reduzir viés, avaliação crítica, montagem e resumo de todos os trabalhos significativos sobre um tema específico. Para Linde e Willich (2003), a revisão sistemática é realizada para impedir prejulgamentos e possibilitar resultados e conclusões mais objetivos. Os mesmos autores afirmam que o produto desse tipo de revisão é consequência da qualidade do material primário; além disso, as decisões tomadas no processo podem intervir nos resultados.

O caráter da pesquisa é descritivo e exploratório. Como conceituadas por Gil (2008), a pesquisa descritiva tem como finalidade a descrição de um fenômeno; já a pesquisa exploratória tem como objetivo possibilitar uma visão generalizada de um fato específico.

Com base nos objetivos da pesquisa, conduziu-se o trabalho a partir do levantamento de estudos associados ao aproveitamento de águas pluviais em edificações. Para isso, seguiu-se a metodologia proposta por Brereton (2007), definindo as questões a serem respondidas com a pesquisa e desenvolvendo um protocolo. Então, foram definidos os critérios para selecionar os artigos e, posteriormente, foram feitas a coleta e a triagem dos documentos encontrados, a análise do conteúdo e a exposição dos resultados.

Para a definição do protocolo e a organização dos estudos encontrados, foi utilizado o software StArt, versão 2.3.4.2. Para a realização desta revisão, definiram-se como palavraschave: saneamento urbano, escassez hídrica, aproveitamento de águas pluviais, aproveitamento de águas pluviais em prédios públicos, aproveitamento de águas pluviais para fins não potáveis em telhados. Essas palavras-chave foram utilizadas como filtro, de modo que, a cada pesquisa realizada, era acrescentada uma expressão no espaço de busca, adicionando o conector and.

Para a busca dos documentos, foi utilizada a base do Google Acadêmico. Apesar dos filtros realizados, o número de arquivos encontrados era muito extenso, portanto, decidiu-se 
colocar entre aspas as expressões "escassez hídrica" e "aproveitamento de águas pluviais", reduzindo de forma considerável os trabalhos a serem analisados. Como foram disponibilizados apenas documentos na língua portuguesa, decidiu-se abranger a pesquisa utilizando as mesmas palavras-chave em inglês e em espanhol.

No software StArt, foram incluídos todos os arquivos encontrados durante a busca. Posteriormente, foram retirados os artigos repetidos, os arquivos indisponíveis gratuitamente e os documentos sem autor. Em seguida, os documentos restantes foram submetidos à análise de alinhamento dos títulos e resumos com a finalidade da pesquisa, descartando aqueles que abordavam a utilização de águas pluviais para fins potáveis, os que não apresentavam os sistemas de aproveitamento de águas pluviais e/ou não discutiam sobre a qualidade da água da chuva. Subsequentemente, foi feita a leitura dos arquivos na íntegra, gerando três quadros contendo nome dos autores, ano e ênfase da pesquisa para cada língua.

\section{RESULTADOS E DISCUSSÃO}

A pesquisa nas três línguas resultou em um total de 36 arquivos em português, 42 em inglês e 6 em espanhol, entre os quais foram selecionados, a partir da metodologia descrita no item anterior, 20 documentos em português, 7 em inglês e 3 em espanhol.

Os Quadros 1, 2 e 3 apresentam um resumo sobre a literatura encontrada, sendo divididas de acordo com a língua utilizada na ferramenta de busca.

\begin{tabular}{|c|c|c|}
\hline AUTORES & ANO & $\begin{array}{c}\hat{E N F A S E ~ D A ~ P E S Q U I S A ~} \\
\end{array}$ \\
\hline BRAGA, E. D & 2009 & $\begin{array}{l}\text { Estuda a viabilidade da implantação do reúso da água e } \\
\text { aproveitamento de águas pluviais em edifícios e } \\
\text { condomínios residenciais. }\end{array}$ \\
\hline CARDOSO, T. O. & 2010 & $\begin{array}{l}\text { Define metodologias para obter consumo de água mais } \\
\text { eficiente em edifícios habitacionais. }\end{array}$ \\
\hline CAVALEIRO, A. R. & 2014 & $\begin{array}{l}\text { Propõe o reúso de águas cinzas e águas pluviais em } \\
\text { edifícios residenciais. }\end{array}$ \\
\hline FONSECA, J. B. G & 2014 & $\begin{array}{l}\text { Analisa a viabilidade da implementação de um sistema de } \\
\text { aproveitamento de águas pluviais. }\end{array}$ \\
\hline GUIMARÃES, J. M. P & 2014 & Analisa a turvação da água pluvial para fins não potáveis. \\
\hline HAFNER, A. V. & 2007 & $\begin{array}{l}\text { Caracterização técnica e econômica de ações para a } \\
\text { conservação de água em edifícios. }\end{array}$ \\
\hline MARTELEIRA, R. G. S. & 2014 & $\begin{array}{l}\text { Avalia a viabilidade da instalação de um sistema de } \\
\text { aproveitamento de águas pluviais. }\end{array}$ \\
\hline MEDEIROS, R. I. B. & 2014 & Avalia a possibilidade de aproveitar águas pluviais. \\
\hline MESQUITA, C. P. et al. & 2013 & $\begin{array}{l}\text { Analisa a qualidade da água de chuva em um pequeno } \\
\text { sistema de captação. }\end{array}$ \\
\hline MOREIRA NETO, R. F. & 2011 & $\begin{array}{l}\text { Avalia o potencial de utilização de água pluvial no } \\
\text { Aeroporto Internacional Tancredo Neves, Confins-MG. }\end{array}$ \\
\hline
\end{tabular}

Quadro 1- Resumo sobre a literatura encontrada, utilizando as palavras-chave em português

Fonte: Elaborado pelos autores (2016).

(Continua..) 
(Continuação)

\begin{tabular}{|c|c|c|}
\hline MURAKAMI, M. F. & 2011 & $\begin{array}{l}\text { Investiga o desempenho de um sistema experimental de } \\
\text { tratamento de água pluvial. }\end{array}$ \\
\hline OLIVEIRA, T. D. et al. & 2015 & Descreve um sistema de aproveitamento de águas pluviais. \\
\hline PEDROSO, A. V. A. & 2014 & $\begin{array}{l}\text { Apresenta um projeto das redes interiores de abastecimento } \\
\text { de água e de drenagem das águas residuais e pluviais de um } \\
\text { edifício. }\end{array}$ \\
\hline ROSA, T. M. & 2012 & $\begin{array}{l}\text { Descreve um sistema de aproveitamento de águas pluviais no } \\
\text { Presídio Central de Porto Alegre e faz o levantamento de } \\
\text { custos do projeto. }\end{array}$ \\
\hline SANTANA, N. C. B. & 2012 & $\begin{array}{l}\text { Analisa a qualidade da água de chuva na cidade de João } \\
\text { Pessoa. }\end{array}$ \\
\hline SANTOS, D. J. C. & 2011 & $\begin{array}{l}\text { Descreve o sistema de aproveitamento de águas pluviais e } \\
\text { faz verificação de qualidade da água captada. }\end{array}$ \\
\hline SORDI, M. & 2016 & $\begin{array}{l}\text { Avaliação de um sistema de aproveitamento de água } \\
\text { pluvial. }\end{array}$ \\
\hline SOUZA, R. L. & 2015 & $\begin{array}{l}\text { Apresenta uma análise comparativa dos métodos de } \\
\text { dimensionamento de reservatório de água pluvial } \\
\text { recomendados pela NBR } 15527 \text {. }\end{array}$ \\
\hline VALÉRIO, D. J. & 2013 & Apresenta formas de gerenciar a água de forma sustentável. \\
\hline YOSHINO, G. H. & 2012 & $\begin{array}{l}\text { Apresenta o dimensionamento do reservatório de águas } \\
\text { pluviais. }\end{array}$ \\
\hline
\end{tabular}

Quadro 1 - Resumo sobre a literatura encontrada, utilizando as palavras-chave em português.

Fonte: Elaborado pelos autores (2016).

\begin{tabular}{|c|c|c|}
\hline AUTORES & ANO & ÊNFASE DA PESQUISA \\
\hline $\begin{array}{l}\text { AHEEYAR, M. M. M.; } \\
\text { BANDARA, M. A. C. }\end{array}$ & 2010 & $\begin{array}{l}\text { Avaliação econômica de projetos de aproveitamento de } \\
\text { águas pluviais. }\end{array}$ \\
\hline ANTUNES, L. N. et al. & 2014 & $\begin{array}{l}\text { Estima o potencial de economia de água potável a partir do } \\
\text { uso de águas pluviais. }\end{array}$ \\
\hline CAMPLING, P. et al. & 2008 & $\begin{array}{l}\text { Avalia riscos e impactos da dessalinização, do reúso de águas } \\
\text { residuais, do aproveitamento de águas pluviais e da recarga de } \\
\text { águas subterrâneas. }\end{array}$ \\
\hline GANGULY, R. et al. & 2014 & $\begin{array}{l}\text { Dimensionamento de um sistema de aproveitamento de } \\
\text { águas pluviais. }\end{array}$ \\
\hline JAULHAC, C. & 2008 & $\begin{array}{l}\text { Apresenta alguns projetos de referência de aproveitamento } \\
\text { de águas pluviais e as normas sobre concepção e aspectos } \\
\text { técnicos. }\end{array}$ \\
\hline LUIS, F. R. & 2014 & Analisa sistemas para a utilização da água da chuva. \\
\hline QUADROS, C. S & 2010 & $\begin{array}{l}\text { Avalia o aproveitamento de águas pluviais e o seu potencial } \\
\text { de utilização no mundo, analisando os seus benefícios } \\
\text { econômicos e ambientais. }\end{array}$ \\
\hline
\end{tabular}

Quadro 2 - Resumo sobre a literatura encontrada, utilizando as palavras-chave em inglês

Fonte: Elaborado pelos autores (2016). 


\begin{tabular}{|l|c|l|}
\hline \multicolumn{1}{|c|}{ AUTORES } & ANO & \multicolumn{1}{c|}{ ÊNFASE DA PESQUISA } \\
\hline $\begin{array}{l}\text { ESPINOSA, K. E. L. } \text { et } \\
\text { al. }\end{array}$ & 2015 & $\begin{array}{l}\text { Estudo da qualidade da água de chuva e dimensionamento } \\
\text { de um sistema de aproveitamento de águas pluviais. }\end{array}$ \\
\hline FERNANDÉZ, P. R. & 2007 & $\begin{array}{l}\text { Analisa a gestão de água em um hotel com o objetivo de } \\
\text { diminuir o consumo de água, propondo a reutilização de } \\
\text { águas residuais e o aproveitamento de águas pluviais. }\end{array}$ \\
\hline $\begin{array}{l}\text { RECIO, J. G.; } \\
\text { SÁNCHEZ, J. } \\
\text { I. C. }\end{array}$ & s.d & $\begin{array}{l}\text { Análise da situação atual de gestão das águas pluviais e } \\
\text { proposta de construção de um sistema de aproveitamento de } \\
\text { água de chuva. }\end{array}$ \\
\hline
\end{tabular}

Quadro 3 - Resumo sobre a literatura encontrada, utilizando as palavras-chave em espanhol Fonte: Elaborado pelos autores (2016).

A partir da leitura dos Quadros 1, 2 e 3, percebe-se que os estudos encontrados são recentes, sendo os mais antigos de 2007. Conforme observado por Liebmann (1979), o aproveitamento e o gerenciamento da água da chuva não são uma prática nova; existem relatos desse tipo de atividade há milhares de anos, antes mesmo da era cristã. Entretanto, segundo Braga (2009), houve uma crescente percepção acerca da limitação do uso da água nas últimas décadas juntamente com uma preocupação com as consequências da urbanização acelerada e com a ameaça da escassez hídrica.

Grande parte dos trabalhos encontrados aborda o uso eficiente da água em edifícios, englobando formas de diminuir perdas de água. Esses trabalhos, além de falarem sobre o aproveitamento de águas pluviais, também discutem sobre o reúso de águas cinzas e formas de conservação da água em edificações. Um exemplo é o trabalho de Hafner (2007). A autora salienta que a correção de vazamentos, a instalação de dispositivos economizadores e a conscientização da comunidade devem ser ações antecedentes à implantação de sistema de aproveitamento de águas pluviais e reúso de águas residuárias. A autora ainda aponta a medição individualizada em prédios como forma de conscientizar o morador, estimulando o uso racional.

Em alguns estudos, como os de Braga (2009) e Cardoso (2010), a pesquisa foi realizada em locais que não existiam sistemas de aproveitamento de águas pluviais. Já em outros, como o de Cavaleiro (2014), a pesquisa foi executada em local que já possuía esses sistemas implantados.

Na pesquisa de Cavaleiro (2014), há o passo a passo de todas as etapas do dimensionamento e da manutenção de um sistema de aproveitamento de água de chuva, além da descrição de um sistema já existente, entretanto, não são apresentados os custos de implantação e manutenção. Oliveira et al. (2015) também abordam em seu artigo apenas 
uma descrição do sistema de aproveitamento de águas pluviais, sem demonstrarem os custos e a análise econômica.

Estudos como os de Fonseca (2014) e Recío e Sánchez (s.d.) evidenciam a economia anual das contas de água quando se opta por utilizar águas pluviais. Contudo, não apontam os gastos com a construção do sistema de aproveitamento de águas de chuva.

Já trabalhos como os de Guimarães (2014), Mesquita et al. (2013) e Santana (2012) discutem apenas acerca da qualidade das águas de chuva. As duas últimas pesquisas, como foram realizadas no Brasil, avaliaram os parâmetros dispostos na NBR 15527/07.

Trabalhos como os de Braga (2009) e Yoshino (2012) demonstraram a inviabilidade econômica dos sistemas de aproveitamento de águas pluviais. Braga (2009) constatou que, em relação ao reúso de águas cinzas, o uso de águas pluviais no condomínio estudado não apresenta viabilidade econômica, já que o período de retorno do investimento é alto e a redução na tarifa de água potável mensal é pequena. Tomaz (2003) afirma que esse tipo de sistema apresenta maior viabilidade em áreas comerciais e industriais, em razão do alto valor que deve ser investido.

Já o estudo de Cardoso (2010) demonstrou que o aproveitamento das águas de chuva é viável em casas e inviável em edifícios, devido à relação entre a área de captação e o número de habitantes. Ou seja, em edifícios com muitos apartamentos essa relação é pequena, inviabilizando o investimento. Os trabalhos de Moreira Neto (2011), Murakami (2011) e Sordi (2016) também apresentaram sistemas de aproveitamento de águas pluviais economicamente viáveis, os quais foram desenvolvidos em um aeroporto, centro de estudo ambiental e universidade, respectivamente.

Rosa (2012) concluiu, em seu estudo, que o tempo de retorno de um sistema de aproveitamento de águas pluviais pode ser elevado; no entanto, é importante realizar pesquisas nesse âmbito para demonstrar a preocupação com o uso racional da água.

Além de reduzir o consumo de água potável, Aheeyar e Bandara (2010) mostraram que o aproveitamento das águas pluviais traz benefícios como a redução de inundações nas cidades, diminuindo assim danos à saúde, lojas, casas, entre outros. Os autores acrescentaram que essas vantagens devem ser incluídas na análise econômica, o que poderia acarretar em uma maior viabilidade do projeto.

Marteleira (2014) utilizou uma ferramenta para analisar a viabilidade da implantação de um sistema de aproveitamento de águas pluviais em um centro universitário. A autora concluiu que o sistema é viável para o centro, já que os reservatórios de combate a incêndio 
já existentes podem ser utilizados como local de armazenamento das águas de chuva. Ela também destaca que há um menor gasto de energia por metro cúbico de água abastecida pela chuva do que a fornecida pela concessionária, e, portanto, há também menores emissões de gases estufa quando se utilizam as águas pluviais.

Os projetos de utilização de águas pluviais também dependem das tarifas impostas pelas concessionárias. Jaulhac (2008) apresenta um panorama global da utilização da água de chuva, evidenciando que, em alguns lugares do mundo, a água potável possui um preço elevado, conduzindo a uma maior viabilidade do uso da água de chuva.

A maioria dos estudos apresentou a coleta de águas pluviais direto do telhado; contudo, Antunes et al. (2014) estudaram a utilização de águas pluviais captadas a partir de pavimentos permeáveis, evidenciando um importante recurso contra a escassez de água.

Luis (2014) apresentou um trabalho interessante, no qual o autor discute sobre o potencial de cidades com quantidade significativa de edifícios altos, como China e Brasil, de aproveitarem o fluxo da água pluvial coletada em tubos para geração de energia elétrica. Posteriormente, essa água coletada pode ser utilizada para fins não potáveis nos prédios. $\mathrm{O}$ autor também salienta que existe viabilidade econômica nesses sistemas; contudo, os benefícios mais significativos são os ambientais.

O reservatório de água da chuva foi dimensionado em muitos estudos por meio do Método Rippl. Entretanto, Souza (2015) desenvolveu um estudo comparativo dos métodos de dimensionamento desses reservatórios, propondo a adoção dos métodos Azevedo Neto ou da Simulação, já que estes apresentaram valores mais próximos da demanda do objeto de estudo.

Dos trabalhos explorados, Espinosa et al. (2015) apresentaram um estudo mais completo, englobando a avaliação da qualidade da água da chuva, o dimensionamento do sistema de aproveitamento de águas pluviais e também uma análise de custo para a construção desse sistema na Facultad de Planeación Urbana y Regional. Os autores atestaram a viabilidade do projeto, além de apresentarem a aceitação do uso de água de chuva pela comunidade acadêmica.

De um modo geral, para estudar a viabilidade de um sistema de aproveitamento de águas pluviais, devem ser levantados os dados de precipitação do município, a demanda de água no local estudado, os dados das áreas de captação de chuva, a avaliação do sistema hidrossanitário já existente, a verificação de qualidade da água da chuva, o dimensionamento do sistema e a análise de viabilidade econômica. 


\section{CONCLUSÃO}

Após interpretação da literatura encontrada, percebeu-se a dimensão que o sistema de aproveitamento de águas pluviais atinge no mundo. Esses sistemas são utilizados não só em edifícios residenciais, mas também em empreendimentos como hospitais, presídios, aeroportos, faculdades, locais turísticos.

Observou-se que existem poucos estudos que discutem todas as dimensões para a implantação de um sistema de aproveitamento de águas pluviais. Grande parte dos estudos aborda somente a verificação da qualidade da água de chuva, outros apresentam a viabilidade econômica e/ou dimensionamento, outros, ainda, descrevem apenas as partes do sistema.

Com base na pesquisa realizada, reafirma-se a necessidade da realização de um trabalho completo, compreendendo desde o balanço da precipitação até a análise de custos e cálculo de viabilidade técnico-econômica para a implantação de um sistema de aproveitamento de águas pluviais.

\section{REFERÊNCIAS}

AGÊNCIA NACIONAL DE ÁGUAS (ANA). Conservação e reúso da água em edificações. São Paulo: Prol Editora Gráfica, 2005. Disponível em: <http://www.gerenciamento.ufba.br/Downloads/manual_agua.pdf>. Acesso em: 24 maio 2016.

AHEEYAR, M. M. M.; BANDARA, M. A. C. S. Economic evaluation of institutional level rainwater harvesting. HARTI Research Report, n. 134. Hector Kobbekaduwa Agrarian Research and Training Institute, Colombo, Sri Lanka, 2010. Disponível em: <https://www.researchgate.net/profile/Mohamed_Aheeyar/publication/2635114 19_Economic_Evaluation_of_Institutional_Level_Rainwater_Harvesting/links/0046353b26e f569d2f00000 0.pdf>. Acesso em: 25 maio 2016.

ANTUNES, L. N.; THIVES, L. P.; GHISI, E. Potential for potable water savings in buildings by using stormwater harvested from porous pavements. Water, Basel, v. 8, n. 4, p. 1-18, mar. 2016. Disponível em: <http://www.mdpi.com/2073-4441/8/4/110/htm>. Acesso: em 26 maio 2016.

BRAGA, E. D. Estudos de reúso de água em condomínios residenciais, 2009, 145 f. Dissertação (Mestrado em Engenharia de Energia) - Universidade Federal de Itajubá, Itajubá, 2009. Disponível em: <http://saturno.unifei.edu.br/bim/0035451.pdf>. Acesso em: 25 maio 2016. 
BRERETON, P. et al. Lessons from applying the systematic literature review process within the V software engineering domain. The Journal of Systems and Software, v. 80, n. 4, p. 571-583, 2007. Disponível em: <http://www.sciencedirect.com/science/article/pii/S016412 120600197X>. Acesso em: 24 maio 2016.

CAMPLING, P. et al. Assessment of the risks and impacts of four alternative water supply options. Task 1 Report, v. 2, 2008. Disponível em: <http://ecologic.eu/sites/files/project/ 2013/task_1_report_March_2009.pdf>. Acesso em: 26 maio 2016.

CARDOSO, T. O. O uso eficiente da água nos edifícios de habitação. 2009. 76 f.

Dissertação (Mestrado em Engenharia Civil) - Universidade Nova de Lisboa, Lisboa, 2010. Disponível em: <https://run.unl.pt/bitstream/10362/5006/1/Cardoso_2010.pdf >. Acesso em: 24 maio 2016.

CAVALEIRO, A. R. Reúso de águas cinzas e águas pluviais em edifícios residenciais. 2014. 163 f. Dissertação (Mestrado em Arquitetura e Urbanismo) - Universidade São Judas Tadeu, São Paulo, 2014. Disponível em: <http:/ /www.usjt.br/biblioteca/mono_disser/mono_ diss/2014/283.pdf>. Acesso em: 26 maio 2016.

COOK, D. J.; MULROW, C. D.; HAYNES, R. B. Systematic Reviews: synthesis of Best Evidence for Clinical Decisions. Annals of Internal Medicine, v. 126, n. 5, p. 376-380, 1997. Disponível em: <http://www.vhpharmsci.com/decisionmaking/Therapeutic_Decision _Making/Intermediate_files/Cook-Systematic\%20ReviewsSynthesis\%20of\%20Best\%20Ev idence\%20for\%20Clinical\%20Decisions- AIM\%201997.pdf>. Acesso em: 24 maio 2016.

ESPINOSA, K. E. L.; LÓPEZ, I. G. O.; AGUILAR, M. M. Diagnóstico de la calidad de agua pluvial e de la red de abastecimento municipal. Diseño de um sistema de captación de agua de lluvia y su aceptación em la comunidade de la Facultad de Planeación Urbana y Regional de la UAEMéx. 2015. Trabalho de Conclusão de Curso (Graduação em Cincias Ambientales) - Universidad Autónoma del Estado de México, Toluca de Lerdo, 2015. Disponível em: <http://ri.uaemex.mx/bitstream/handle/20.500.11 799/23992/UAEM-FAPUR-TESIS-LUNA\% 2cORDO\%C3\% 91EZ\%2cROMERO.pdf?se quence $=1 \&$ is Allowed $=\mathrm{y}>$. Acesso em: 25 maio 2016.

FERNANDÉZ, P. R. Diseño de un sistema integrado de aprovechamiento de aguas grises y pluviales en el hotel rural de Son Xotano (Sencelles, Mallorca). 2007. 109 f. Dissertação (Mestrado em Engenharia Industraial) - Escola Tècnica Superior d'Enginyeria Industrial de Barcelona, Barcelona, 2007. Disponível em:

<http://upcommons.upc.edu/handle/2099.1/4553>. Acesso em: 25 maio 2016.

FONSECA, J. B. G. Contribuição para a redução dos consumos de água da rede, através da utilização de águas pluviais. 2014. 116 f. Dissertação (Mestrado em Engenharia do Ambiente) - Universidade Nova de Lisboa, Lisboa, 2014. Disponível em: <https://run.unl.pt/bitstream/10362/13099/1/Fonseca_2014.pdf> Acesso em: 24 maio 2016. 
GANGULY, R. et al. Application of rain water harvesting scheme in Shimla region. Hydrology: Current Research, v. 5, n. 3, set. 2014. Disponível em:

<http://dx.doi.org/10.4172/2157-7587.1000180>. Acesso em: 26 maio 2016.

GIL, A. C. Métodos e técnicas de pesquisa social. 6. ed. São Paulo: Atlas, 2008.

GUIMARÃES, J. M. P. Análise da turvação da água num dispositivo de first flush com filtro incorporado para utilização em sistemas de aproveitamento de águas pluviais. 2014. 90 f. Dissertação (Mestrado em Engenharia Civil) - Universidade do Minho, Braga, 2014. Disponível em: <http://repositorium.sdum.uminho.pt/bitstream/1822/36271/1/Disserta \%C3\%A7\%C3\%A3o_J os\%C3\%A9\%20Guimar\%C3\%A3es_2014.pdf >. Acesso em: 24 maio 2016.

HAFNER, A. V. Conservação e reúso de água em edificações - experiências nacionais einternacionais. 2007. 161f. Dissertação (Mestrado em Engenharia Civil) - Universidade Federal do Rio de Janeiro, Rio de Janeiro, 2007. Disponível em: <http://wwwp.coc.ufrj.br/teses/mestrado/rh/2007/Teses/HAFNER_AV_07_t_M_rhs.pdf>. Acesso em: 26 maio 2016.

JAULHAC, C. Project acronym: WSSTP activities on alternative water resources. Berlim,2008. Disponível em: <http://www.kompetenzwasser.de/fileadmin/user_upload /pdf/forschung/WssTP/RWHM_revi ew_report_Claire_Jaulhac.pdf>. Acesso em: 25 maio 2016.

LIEBMANN, H. Terra um Planeta inabitável? Da antiguidade até os nossos dias toda a trajetória poluidora da humanidade. Tradução: Flávio Meurer. Rio de Janeiro: Biblioteca do Exército, 1979. 181 p.

LINDE, K.; WILLICH, S. N. How objective are systematic reviews? Differences between reviews on complementary medicine. Journal of the Royal Society of Medicine, v. 96, n. 1, p. 17-22, 2003. Disponível em:

<http://www.ncbi.nlm.nih.gov/pmc/articles/PMC539366/\#ref1>. Acesso em: 27 maio 2016.

LUIS, F. R. Contributions to sustainable use of water. 2014. 86f. Dissertação (Mestrado em Engenharia Civil) - Instituto Superior Técnico, Lisboa, 2014. Disponível em: $<$ https://fenix.tecnico.ulisboa.pt/downloadFile/563345090412772/Dissertacao.pdf >. Acesso em: 26 maio 2016.

MARTELEIRA, R. G. S. Avaliação do binómio água-energia de um sistema de aproveitamento de águas pluviais - estudo de caso do Campus do IST no Taguspark. 2014. 96 f. Dissertação (Mestrado em Engenharia do Ambiente) - Universidade Nova de Lisboa, Lisboa, 2014. Disponível em: <https://run.unl.pt/bitstream/10362/13199 /1/Marteleira_2014.pdf>. Acesso em: 25 maio 2016. 
MEDEIROS, R. I. B. Contribuição para a diminuição do consumo de água potável Caso de estudo de aproveitamento de águas pluviais no Município de Setúbal. 2014. 116f. Dissertação (Mestrado em Engenharia do Ambiente) - Universidade Nova de Lisboa, Lisboa, 2014. Disponível em: <https://run.unl.pt/bitstream/10362/14261/1/Medeiros_2 014.pdf >. Acesso em: 24 maio 2016.

MESQUITA, C. P.; FONSECA, M.; MORIOKA, T. Y. Análise de qualidade da água de chuva, visando o uso residencial sustentável. 2013. 87 f. Trabalho de Conclusão de Curso (Graduação em Engenharia Civil) - Universidade Anhembi Morumbi, São Paulo, 2013. Disponível em: <http://engenharia.anhembi.br/tcc-131/civil-02.pdf>. Acesso em: 24 maio 2016.

MOREIRA NETO, R. F. Avaliação do aproveitamento de água pluvial em complexos aeroportuários. 2011. 78 f. Dissertação (Mestrado em Engenharia Civil) - Universidade Federalde Viçosa, Viçosa, 2011. Disponível em: <http://www.locus.ufv.br/bitstream/handle $/ 123456789 / 3756 /$ texto\%20completo.pdf? sequence=1\&isAllowed=y $>$. Acesso em: 24 maio 2016.

MURAKAMI, M. F. Avaliação de desempenho de uma unidade em escala real para tratamento de água pluvial empregando a filtração rápida por meio de filtro de pressão e amido natural de milho como coagulante. 2011. $81 \mathrm{f}$. Dissertação (Mestrado em Engenharia Urbana) - Universidade Federal de São Carlos, São Carlos, 2011. Disponível em:<http://www.bdtd.ufscar.br/htdocs/tedeSimplificado/tde_arquivos/11/TDE-20110208T160835Z-3501/Publico/3409.pdf >. Acesso em: 26 maio 2016.

OLIVEIRA, T. D.; CHRISTMANN, S. S.; PIEREZAN, J. B. Aproveitamento, captação e (re) uso das águas pluviais na arquitetura. Revista Gestão e Desenvolvimento em Contexto - GEDECON, Cruz Alta, v. 2, n. 2, p. 1-15, 2014. Disponível em: <http://revistaeletronica.unicruz.edu.br/index.php/GEDECON/article/view/1933/497>. Acesso em: 24 maio 2016.

PEDROSO, A. V. A. Uso eficiente da água num edifício de habitação. 2014.72 f.

Dissertação (Mestrado em Engenharia Civil) - Instituto Superior de Engenharia de Lisboa, Lisboa, 2014. Disponível em: <http://repositorio.ipl.pt/handle/10400.21/4694>. Acesso em: 26 maio 2016.

QUADROS, C. S. Rainwater harvesting, case study: FCT/UNL Campus. 2010. 133 f. Dissertação (Mestrado em Engenharia Ambiental) - Universidade Nova de Lisboa, Lisboa, 2010. Disponível em: <https://run.unl.pt/bitstream/10362/4799/1/Quadros_2010.pdf〉. Acesso em: 25 maio 2016.

RECIO, J. G.; SÁNCHEZ, J. I. C. Sistemas de aprovechamiento de aguas pluviales. [s.d.]. 59 f. Dissertação (Mestrado em Ingeniería del Agua) - Universidad de Sevilla, Sevilla, [s.d.]. Disponível em: <http://sistemamid.com/panel/uploads/biblioteca/1/99/100/6331.pdf>. Acesso em: 25 maio 2016. 
ROSA, T. M. Reaproveitamento de águas pluviais: custo de implantação deste sistema no presídio central de Porto Alegre. 2012. 72 f. Trabalho de Conclusão de Curso (Graduação em Engenharia Civil) - Universidade Federal do Rio Grande do Sul, Porto Alegre, 2012. Disponível em: <http://www.lume.ufrgs.br/bitstream/handle/10183/79787/000897529. pdf? sequence $=1>$. Acesso em: 24 maio 2016.

SANTANA, N. C. B. Qualidade das águas de chuva em João Pessoa - PB: estudo comparativo com padrões de qualidade para uso residencial. 2012. 83 f. Dissertação (Mestrado em Engenharia Urbana e Ambiental) - Universidade Federal da Paraíba, João Pessoa, 2012. Disponível em: <http://tede.biblioteca.ufpb.br:8080/handle/tede/5464 \#preview-link0>. Acesso em: 25 maio 2016.

SANTOS, D. J. C. Aplicação de medidas de eficiência hídrica em meio hospitalar: o caso do aproveitamento de águas pluviais. 2011. 147f. Dissertação (Mestrado em Saúde Ocupacional) - Universidade de Coimbra, Coimbra, 2011. Disponível em: $<$ https://eg.sib.uc.pt/bitstream/10316/20130/1/SO_aproveitamento\%20de\%20\%C3\%81guas $\%$ 20Pluviais.pdf $>$. Acesso em: 24 maio 2016.

SORDI, M. Análise de um sistema de aproveitamento de água pluvial no Centro de Integração Acadêmica da UEPB, Campina Grande - Paraíba. 2016. 48 f. Trabalho de Conclusão de Curso (Graduação em Engenharia Sanitária e Ambiental) - Universidade Estadual da Paraíba, Campina Grande, 2016. Disponível em: <http://dspace.bc.uepb.edu.br/jspui/bitstream/123456789/9013/1/PDF\%20$\% 20$ Mariah\%20 de\%20Sordi.pdf $>$. Acesso em: 24 maio 2016.

SOUZA, R. L. Análise comparativa dos métodos de dimensionamento de reservatórios para aproveitamento de águas pluviais: estudo de caso Hospital Federal do Andaraí/RJ. 2015. 136f. Dissertação (Mestrado em Engenharia Urbana) - Universidade Federal do Rio de Janeiro, Rio de Janeiro, 2015. Disponível em: <http://dissertacoes.poli.ufrj.br/dissertacoes /dissertpoli1520.pdf>. Acesso em: 24 maio 2016.

TOMAZ, P. Aproveitamento da Água de Chuva. São Paulo: Navegar, 2003.

TUCCI, C. E. M. et al. Cenários da gestão da água no Brasil: uma contribuição para a "visão mundial da água”. Revista Brasileira de Recursos Hídricos. v. 5, n. 3, p. 31-43, jul/set. 2000. Disponível em: <http://rhama.net/download/artigos/artigo29.pdf>. Acesso em: 24 maio 2016.

VALÉRIO, D. J. Gestão sustentável da água em empreendimentos turísticos. 2013. Dissertação (Mestrado em Engenharia Civil) - Instituto Superior de Engenharia de Lisboa, Lisboa, 2015. Disponível em: <https://repositorio.ipl.pt/handle/10400.21 /2550>. Acesso em: 26 maio 2016.

YOSHINO, G. H. O aproveitamento de água de chuva para fins não potáveis na cidade universitária Professor José da Silveira Netto - Belém/PA. 2012. 121f. Dissertação (Mestrado em Engenharia Civil) - Universidade Federal do Pará, Belém, 2012. Disponível em: <http://www.repositorio.ufpa.br:8080/jspui/bitstream/2011/3541/3/Dissertacao_Aproveit ame ntoAguaChuva.pdf>. Acesso em: 24 maio 2016. 


\title{
ASSESSMENT OF RAINWATER HARVESTING THROUGH A SYSTEMATIC REVIEW OF THE LITERATURE
}

\begin{abstract}
The water is essential for the survival of species and for economic and social development. Although the Earth's surface is consists of three quarters of water, only a small portion can be used for human activities. Due to urban pressures, pollution of water sources and poor management, currently, many cities have suffered with the water crisis. An alternative to reduce pressures on water resources is the use of rainwater for non-potable purposes. Knowing this, the aim of this study was to conduct a systematic review of the literature to identify research related to the theme. Among the works found, 20 studies were selected in Portuguese, 7 in English and three in Spanish. It was observed that there are few studies that discuss all aspects for the implementation of a rainwater utilization system. Some works only analyze the rainwater quality, others just consider the parts of the system without providing scaling or economic viability. Therefore, there is the need for a study to discuss all stages of implementation of a recovery system of rainwater.
\end{abstract}

Keywords: Water scarcity. Rainfall. Water supply.

Recebido em: 24/06/2016

Aprovado em: 15/07/2016

Publicado em: 06/10/2017 